\title{
Non-alcoholic fatty liver disease and thyroid function in adult patients
}

\author{
Feras Alhussainy ${ }^{1}$, Razan Alharbi ${ }^{2}$, Abrar Alali $^{3}$, Mohammad Almutairi $^{4}$, Mohammed Aljawi ${ }^{5}$, \\ Youssef Almodhaibri ${ }^{6}$, Semat Bakri ${ }^{3}$, Shahad Alghamdi ${ }^{3}$, \\ Abdulrahman Alshahrani ${ }^{7}$, Omar Zainal ${ }^{1}$
}

\author{
${ }^{1}$ Arabian Gulf University, Bahrain \\ ${ }^{2}$ Almaarefa College, Riyadh, KSA \\ ${ }^{3}$ King Khalid University, Abha, KSA \\ ${ }^{4}$ Medical University of Warsaw, Poland \\ ${ }^{5}$ Taif University, Taif, KSA \\ ${ }^{6}$ Qassim University, Qassim, KSA \\ ${ }^{7}$ AL Bashaier General Hospital, Bisha, KSA
}

Received: 06 May 2018

Accepted: 25 May 2018

\section{*Correspondence:}

Dr. Feras Alhussainy,

E-mail: feras-117@windowslive.com

Copyright: (C) the author(s), publisher and licensee Medip Academy. This is an open-access article distributed under the terms of the Creative Commons Attribution Non-Commercial License, which permits unrestricted non-commercial use, distribution, and reproduction in any medium, provided the original work is properly cited.

\begin{abstract}
Results from published studies on the association between non-alcoholic fatty liver disease and hypothyroidism are still controversial. Thyroid dysfunction is closely related with components of metabolic syndrome. We conducted this meta-analysis using a comprehensive search of EMBASE, MEDLINE, PubMed, Cochrane Database of Systematic Reviews, and Cochrane Central Register of Controlled Trials till 31 January 2018 for prospective observational studies that evaluated the relationship of non-alcoholic fatty liver disease and thyroid function in adult patients. Thirteen studies were included in the present meta-analysis. Meta-analysis of the 13 studies found a high correlation between hypothyroidism and NAFLD (OR=1.48, 95\% CI 1.22-1.91, p<0.001). In the meta-regression analyses, we found that study design was a possible source of heterogeneity $(\mathrm{p}=0.17)$, but other covariates were not. The present meta-analysis provides strong epidemiological evidence for the relationship between hypothyroidism and NAFLD. Both individuals with subclinical and overt hypothyroidism are at higher risk for NAFLD than euthyroid subjects.
\end{abstract}

Keywords: Meta-analysis, Non-alcoholic fatty liver disease, Hypothyroidism, Subclinical hypothyroidism

\section{INTRODUCTION}

The frequency of non-alcoholic fatty liver disease (NAFLD) has increased significantly throughout the past periods, and it has become the prominent reason of liver disease worldwide with a global prevalence of $25 \%$, which can be moderately recognized to the rising prevalence of obesity. ${ }^{1,2}$ The term NAFLD at the histological level includes a spectrum of liver damage containing in its common form, or simple steatosis, in addition to nonalcoholic steatohepatitis (NASH), a theoretically progressive form of NAFLD defined by the occurrence steatosis along with hepatocyte ballooning, inflammation and variable degrees of fibrosis. Notably, the occurrence of obesity at least doubles the prevalence of NASH and its progression to cirrhosis, liver failure and hepatocellular carcinoma. ${ }^{3}$ NAFLD can be categorized into two main histological categories, to be exact nonalcoholic fatty liver and nonalcoholic steatohepatitis, which is the progressive subtype of NAFLD and can further induce liver cirrhosis and hepatocellular carcinoma. ${ }^{4}$ 
An expanding number of illnesses have been accounted for to be connected to NAFLD, for example, cancer, cardiovascular ailment, type 2 diabetes, and chronic kidney ailment. ${ }^{5,6}$ The treatment and prevention of NAFLD have turned into the focal point of medicinal research as of late, and distinguishing the hazard factors for NAFLD is basic to create viable preventive intercessions against NAFLD. Metabolic disorders, for example, hyperlipidemia, hypertension diabetes, central obesity, and gallstones are known risk factors for NAFLD. ${ }^{7,8}$ Thyroid hormones control all metabolic paths, acting on carbohydrates, protein and lipid metabolism. Low thyroid hormone levels are related with hypometabolism categorized by decreased weight gain, resting energy expenditure, reduced lipolysis, increased cholesterol levels, and reduced gluconeogenesis. ${ }^{9}$ Thyroid hormones similarly have a role in hepatic lipid metabolism and hepatic insulin resistance. ${ }^{10}$

The relationship amongst hypothyroidism and NAFLD risk stays in debate up to now. Therefore, the present meta-analysis is to validate the association amongst hypothyroidism and NAFLD.

\section{METHODS}

\section{Data sources and searches}

We conducted this meta-analysis using a comprehensive search of EMBASE, MEDLINE, PubMed, Cochrane Database of Systematic Reviews, and Cochrane Central Register of Controlled Trials till 31 January 2018 for prospective observational studies that evaluated the relationship of Nonalcoholic fatty liver disease and thyroid function in adult patients. Both semiparametric and parametric methods were used. No language restrictions were imposed. We followed the standard guidelines for conducting and reporting meta-analyses of observational studies. ${ }^{11}$

\section{Selection criteria}

Studies were included in this meta-analysis if they satisfied the following criteria: cohort, cross-sectional, or case-control studies which investigated the association between hypothyroidism and NAFLD in adult participants, and the investigators reported relative risks (RRs) with 95\% CI, the diagnosis of hypothyroidism must be based on biochemical tests including TSH levels and T4/FT4 levels. Included NAFLD patients must be diagnosed with an ultrasound examination or Liver biopsy to make a clear definite diagnosis.

\section{Data extraction}

The final data were abstracted from each study using standardized form: the first author's name, year of publication, study design, study location, number of participants, participant baseline characteristics (age and gender), method used to identify and verify NAFLD as well as thyroid function, definition of hypothyroidism including overt hypothyroidism or subclinical hypothyroidism. Flow diagram showing the selection criteria of assessed studies. $^{12}$

\section{Statistical analysis}

The present meta-analysis utilized Stata version 12.0 software for statistical analysis. Mean difference (MD) were calculated for continuous variables. Pooled odds ratios (OR) were calculated for discrete variables. Heterogeneity amongst the trials was determined by means of the Cochran $\mathrm{Q}$ value and quantified using the $\mathrm{I}^{2}$ inconsistency test with a significance set at the P-value $<0.10$ or $\mathrm{I}^{2}$ score $>50 \%$. ${ }^{13}$ DerSimonian-Laird randomeffect meta-analysis was adopted when obvious heterogeneity existed. ${ }^{14}$

\section{RESULTS}

We recognized 988 citations using the search strategy. Of these, we excluded 365 after examining the title and abstract including removal of duplicates. We retrieved and evaluated 31 articles in more detail, of which 18 articles were excluded, leaving 13 studies that were eligible for inclusion (Figure 1). ${ }^{15-27}$ Main characteristics of included studies have been summarized in Table 1 and 2.

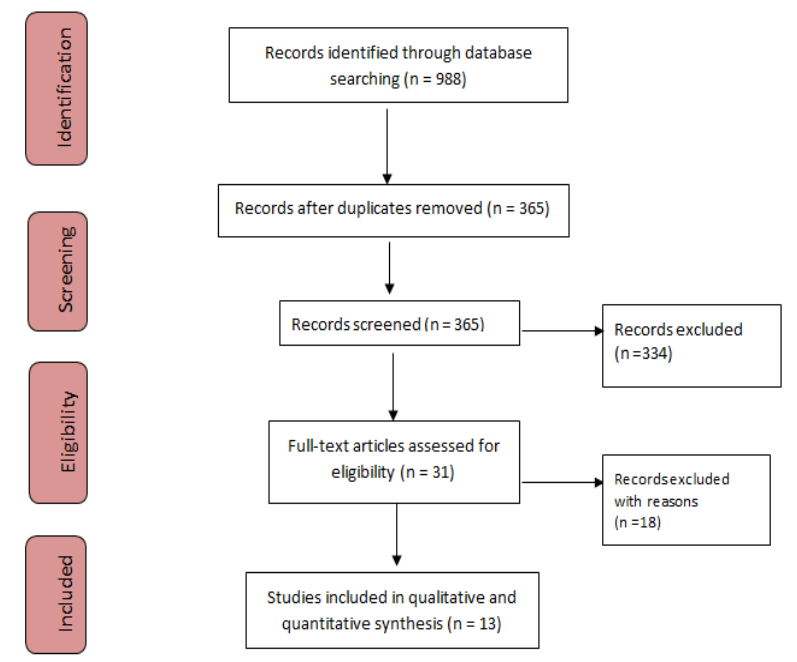

Figure 1: Flow diagram showing the selection criteria of assessed studies.

Meta-analysis of the 13 studies found a high correlation between hypothyroidism (including both overt hypothyroidism and subclinical hypothyroidism) and NAFLD $(O R=1.48,95 \%$ CI 1.22-1.91, $\mathrm{p}<0.001)$

Obvious heterogeneity was found among these 13 studies $\left(\mathrm{I}^{2}=75.1 \%\right.$; $\mathrm{p}<0.001$, Table 4$)$. In the meta-regression analyses, we found that study design was a possible source of heterogeneity $(\mathrm{p}=0.17)$, but other covariates were not. 
Table 1: Characteristics of included studies.

\begin{tabular}{|lllll|}
\hline Study & Year & Country & Mean age, years \pm SD & Study design \\
\hline Moustafa $^{\mathbf{1 5}}$ & 2009 & Egypt & $55 \pm 4.6$ & Case-control \\
\hline Gokmen $^{\mathbf{6}}$ & 2016 & Turkey & $49.9 \pm 12.5$ & Cross-sectional \\
\hline Bano $^{\mathbf{1 7}}$ & 2016 & Netherlands & $64.7 \pm 9.2$ & Cohort \\
\hline Ludwig $^{\mathbf{1 8}}$ & 2015 & Germany & $41.3 \pm 12.6$ & Cross-sectional \\
\hline Liu $^{\mathbf{9}}$ & 2015 & China & $45.4 \pm 10.3$ & Cross-sectional \\
\hline Pagadala $^{\mathbf{2 0}}$ & 2012 & US & $50.4 \pm 10.4$ & Case-control \\
\hline Ittermann $^{\mathbf{2 1}}$ & 2013 & Germany & $50.5 \pm 16.6$ & Cross-sectional \\
\hline $\mathbf{X u}^{\mathbf{2 2}}$ & 2011 & China & $71.7 \pm 4.1$ & Cross-sectional \\
\hline Chung $^{\mathbf{2 3}}$ & 2012 & Korea & $48.6 \pm 11.8$ & Cross-sectional \\
\hline Eshraghian $^{24}$ & 2013 & Iran & $48.2 \pm 12.8$ & Cross-sectional \\
\hline Wang $^{\mathbf{2 5}}$ & 2014 & China & $56.99 \pm 7.98$ & Cross-sectional \\
\hline Posadas-Romero $^{\mathbf{2 6}}$ & 2014 & Mexico & $51.9 \pm 8.1$ & Cross-sectional \\
\hline Parikh $^{\mathbf{2 7}}$ & 2015 & India & $44.3 \pm 3.2$ & Case-control \\
\hline
\end{tabular}

Table 2: Definition of hypothyroidism and diagnosis of NAFLD.

\begin{tabular}{|c|c|c|c|}
\hline Study & Definition of hypothyroidism & $\begin{array}{l}\text { Diagnosis of } \\
\text { NAFLD }\end{array}$ & Adjusted factors \\
\hline Moustafa $^{15}$ & N/A & Ultrasound & Age, gender \\
\hline Gokmen $^{16}$ & $\mathrm{TSH}>4.1 \mathrm{mIU} / \mathrm{L}$ & Ultrasound & Age, gender \\
\hline Bano $^{17}$ & $\begin{array}{l}\mathrm{TSH}>4.0 \mathrm{mIU} / \mathrm{L} \text { and } \mathrm{FT} 4 \\
\text { levels }<0.85 \mathrm{ng} / \mathrm{dl}\end{array}$ & Ultrasound & $\begin{array}{l}\text { Age, sex, cohort, follow-up time, } \\
\text { use of hypolipidemic drugs and } \\
\text { cardiovascular }\end{array}$ \\
\hline Ludwig $^{18}$ & $\begin{array}{l}\text { TSH >34 IU/mL Total T4 12.8-20.4 } \\
\mathrm{pmol} / \mathrm{L} \text { Total T3 3.9-6.7 } \mathrm{pmol} / \mathrm{L}\end{array}$ & Ultrasound & Age, gender, BMI \\
\hline Liu $^{19}$ & $\begin{array}{l}\text { TSH }>4.78 \mathrm{mIU} / \mathrm{L} \text { FT3 } 3.5-6.5 \mathrm{pmol} / \mathrm{L} \text { FT4 } \\
11.5-22.7 \mathrm{pmol} / \mathrm{L}\end{array}$ & Ultrasound & $\begin{array}{l}\text { Age, gender, smoking, HTN, BMI, } \\
\text { FBG, TG, TC, LDL, HDL, blood } \\
\text { urea nitrogen, Cr, uric acid }\end{array}$ \\
\hline Pagadala $^{20}$ & Overt hypothyroidism & Histological & $\begin{array}{l}\text { Gender, ethnicity, diabetes, HTN, } \\
\text { hyperlipidemia, and hypothyoidism } \\
\text { and mean (SD) }\end{array}$ \\
\hline Ittermann $^{21}$ & TSH >3 mIU/L FT4 7.7-23.2 pmol/L & Ultrasound & $\begin{array}{l}\text { Age, physical activity, WC, alcohol } \\
\text { use, food intake pattern }\end{array}$ \\
\hline $\mathbf{X u}^{22}$ & $\mathrm{TSH}>4.5 \mathrm{mIU} / \mathrm{L}$ FT4 & Ultrasound & $\begin{array}{l}\text { Waist circumference, systolic blood } \\
\text { pressure, diastolic blood pressure, } \\
\text { triglyceride, HDL cholesterol, and } \\
\text { fasting plasma glucose }\end{array}$ \\
\hline Chung ${ }^{23}$ & $\begin{array}{l}\text { TSH }>4.1 \mathrm{mIU} / \mathrm{L} \text { and FT } 4 \\
0.7-1.8 \mathrm{ng} / \mathrm{dL}\end{array}$ & Ultrasound & $\begin{array}{l}\text { Age, gender, BMI, triglyceride, } \\
\text { hyperlipidemia, hypertension, DM }\end{array}$ \\
\hline Eshraghian $^{24}$ & $\mathrm{TSH}>5.2 \mathrm{mIU} / \mathrm{L}$ FT4 $<11.5 \mathrm{pmol} / \mathrm{L}$ & Ultrasound & $\begin{array}{l}\text { HTN, DM, HLD, ischemic heart } \\
\text { disease }\end{array}$ \\
\hline Wang $^{25}$ & TSH $>4.2 \mu \mathrm{UmL}$, FT4: $12-22$ & Ultrasound & Age, gender \\
\hline $\begin{array}{l}\text { Posadas- } \\
\text { Romero }^{26}\end{array}$ & $\mathrm{TSH}>4.5 \mathrm{mIU} / \mathrm{L}$ & $\begin{array}{l}\text { Enzymatic } \\
\text { procedures }\end{array}$ & Age, gender \\
\hline Parikh $^{27}$ & $\mathrm{TSH}>10 \mathrm{IU} / \mathrm{mL}$ & Ultrasound & $\begin{array}{l}\text { Age, gender, alcohol use, and serum } \\
\text { triglycerides }\end{array}$ \\
\hline
\end{tabular}

As we performed sensitivity analysis, statistically similar results were obtained after sequentially excluding each study at a time in all meta-analyses for FT3, FT4, and TSH, suggesting the results were robust. For assessing the studies for the MD of FT3 and FT4, publication biases are present as there are more studies that favor negative results (decreased FT3 and FT4 in NAFLD compared with controls) but the Egger regression tests showed nonsignificant publication bias $(\mathrm{p}=0.65$ and $\mathrm{p}=0.78$, respectively). For assessing the MD of TSH, the plot excludes bias with the nonsignificant Egger test $(\mathrm{p}=0.94)$. 
Table 3: The relationship between hypothyroidism and NAFLD.

\begin{tabular}{|c|c|c|}
\hline Study & OR & $95 \% \mathrm{CI}$ \\
\hline Moustafa $^{15}$ & 0.35 & $(0.24-0.94)$ \\
\hline Gokmen $^{16}$ & 1.01 & $(0.51-2.32)$ \\
\hline Bano $^{17}$ & 1.24 & $(1.01-1.53)$ \\
\hline Ludwig $^{18}$ & 1.12 & $(0.65-2.17)$ \\
\hline Liu $^{19}$ & 0.28 & $(0.25-0.33)$ \\
\hline Pagadala $^{20}$ & 2.10 & $(1.10-3.90)$ \\
\hline Ittermann ${ }^{21}$ & 2.09 & $(1.22-3.60)$ \\
\hline $\mathbf{X u}^{22}$ & 2.21 & $(1.42-3.44)$ \\
\hline Chung ${ }^{23}$ & 1.38 & $(1.17-1.62)$ \\
\hline Eshraghian $^{24}$ & 1.01 & $(0.55-1.86)$ \\
\hline Wang $^{25}$ & 1.23 & $(0.87-1.73)$ \\
\hline Posadas-Romero ${ }^{26}$ & 0.83 & $(0.55-1.25)$ \\
\hline Parikh $^{27}$ & 14.94 & $(3.55-62.60)$ \\
\hline
\end{tabular}

Table 4: Summary of the association between hypothyroidism and NAFLD.

\begin{tabular}{|c|c|c|c|c|}
\hline \multirow[t]{2}{*}{ Outcomes } & \multicolumn{2}{|l|}{ Pooled estimates } & \multicolumn{2}{|c|}{ Heterogeneity } \\
\hline & OR (95\% CI) & $P$ value & $I^{2}(\%)$ & $P$ value \\
\hline \multicolumn{5}{|l|}{ Overt hypothyroidism } \\
\hline Total studies & $1.65(1.19-2.42)$ & $<0.002$ & 35.7 & 0.17 \\
\hline Studies with adjustment & $1.78(1.28-2.41)$ & $<0.001$ & 37.8 & 0.19 \\
\hline \multicolumn{5}{|c|}{ Subclinical hypothyroidism } \\
\hline Total studies & $1.38(1.08-1.68)$ & $<0.006$ & 0.69 & $<0.001$ \\
\hline Studies with adjustment & $1.59(1.21-2.19)$ & $<0.002$ & 79.5 & $<0.001$ \\
\hline \multicolumn{5}{|l|}{ Hypothyroidism } \\
\hline Total studies & $1.48(1.18-1.79)$ & $<0.001$ & 74.8 & $<0.001$ \\
\hline Studies with adjustment & $1.65(1.41-2.18)$ & $<0.001$ & 78.8 & $<0.001$ \\
\hline
\end{tabular}

\section{DISCUSSION}

Though earlier investigations suggest that hypothyroidism may assume a critical part in the pathogenesis of NAFLD, some observational examinations neglect to locate an obvious relationship between hypothyroidism and NAFLD. Nevertheless, based on the outcomes of the current study, hypothyroidism assumes a critical part in the pathogenesis of NAFLD. The meta-analysis recommends epidemiological indication for the noticeable association between hypothyroidism and NAFLD, and the influence of hypothyroidism is independent from other recognized risk features for NAFLD. In addition, both subclinical hypothyroidism and overt hypothyroidism are autonomously linked to NAFLD. Our outcomes exhibit that either overt hypothyroidism or subclinical hypothyroidism freely builds the risk of NAFLD. A few examinations have established the framework for the discoveries of the investigation by giving some conceivable clarifications to the molecular mechanism underlying the connection amongst hypothyroidism and NAFLD. There are a few conceivable systems which can clarify the connection amongst hypothyroidism and NAFLD. Evident relations amongst hypothyroidism and metabolic changes have been accounted for, which incorporate IR, dyslipidemia and weight and they have imperative parts in the advancement of NAFLD. ${ }^{28}$

Even though hypothyroidism is allied with mechanisms of metabolic syndrome and NAFLD is reflected as the hepatic manifestation of metabolic syndrome, while there are numerous reasonable mechanisms that could clarify this conceivable relation, the present study, which included all published observational studies, found a strong epidemiological evidence association between NAFLD and hypothyroidism. Leptin is considered as one of the explanations of this association because it is found to be increased in patients with hypothyroidism and it is also found to be higher in NAFLD as it can promote hepatic insulin resistance and be involved in hepatic fibrogenesis. ${ }^{29}$ Both IR and obesity are dynamic factors in the development of NAFLD, which are similarly mutual in hypothyroidism patients compared to those general populations. IR can increase liver injury in NAFLD. Besides, Demir et al. found that hypothyroidism can cause NAFLD in rat models, and pointed out that obesity is one of the key factors in the association between hypothyroidism and NAFLD. ${ }^{30}$

As per the outcomes of the current study, we found a conspicuous occurrence that the relationship between 
overt hypothyroidism and NAFLD was more noteworthy than that between subclinical hypothyroidism and NAFLD. As stated above, overt hypothyroidism is characterized as having a considerably higher TSH level and lower T4 and T3 levels contrasted with subclinical hypothyroidism. The more huge relationship between overt hypothyroidism and NAFLD might be clarified by the synergistic impacts of higher TSH level and lower thyroid hormones in the pathogenesis of NAFLD, on the grounds that TSH itself may incite hepatocyte steatosis by means of $\mathrm{TSH}$ receptor flag. ${ }^{31}$

\section{CONCLUSION}

The present meta-analysis our meta-analysis provides strong epidemiological evidence for the significant relationship between hypothyroidism and NAFLD. Both individuals with subclinical hypothyroidism and overt hypothyroidism are at a higher risk for the development of NAFLD than those with normal thyroid function. To confirm these results, further studies should be made to make a better understanding to further strengthen the relationship between NAFLD and hypothyroidism. Large-scale and long-term randomized controlled trials in various populations must be carried out in future studies to deliver more significant evidence.

Funding: No funding sources

Conflict of interest: None declared

Ethical approval: Not required

\section{REFERENCES}

1. Younossi ZM, Koenig AB, Abdelatif D, Fazel Y, Henry L, Wymer M. Global epidemiology of nonalcoholic fatty liver disease - meta-analytic assessment of prevalence, incidence, and outcomes. Hepatology. 2016;64:73-84.

2. Rinella ME. Nonalcoholic fatty liver disease: a systematic review. JAMA. 2015;313(22):2263-73.

3. Barrera F, George J. Non-alcoholic fatty liver disease: more than just ectopic fat accumulation. Drug Discov. 2013;10:47-54.

4. Charlton MR, Burns JM, Pedersen RA, Watt KD, Heimbach JK, Dierkhising RA. Frequency and outcomes of liver transplantation for nonalcoholic steatohepatitis in the United States. Gastroenterology. 2011;141(4):1249-53.

5. Motamed N, Rabiee B, Poustchi H, Dehestani B, Hemasi GR, Khonsari MR, et al. Non-alcoholic fatty liver disease (NAFLD) and 10-year risk of cardiovascular diseases. Clin Res Hepatol Gastroenterol. 2017;41(1):31-8.

6. Adams LA, Anstee QM, Tilg H, Targher G. Nonalcoholic fatty liver disease and its relationship with cardiovascular disease and other extrahepatic diseases. Gut. 2017;66(6):1138-53.

7. Jaruvongvanich V, Sanguankeo A, Upala S. Significant association between gallstone disease and nonalcoholic fatty liver disease: a systematic review and meta-analysis. Dig Dis Sci. 2016;61:2389-96.

8. Angulo P. Nonalcoholic fatty liver disease. N Engl J Med. 2002;346:1221-31.

9. Pucci E, Chiovato L, Pinchera A. Thyroid and lipid metabolism. Int $\mathrm{J}$ Obes Relat Metab Disord. 2000;24(2):109-12.

10. Sinha RA, Singh BK, Yen PM. Thyroid hormone regulation of hepatic lipid and carbohydrate metabolism. Trends Endocrinol Metab. 2014;25:538-5.

11. Stroup DF, Berlin JA, Morton SC, Olkin I, Williamson GD, Rennie D, et al. Meta-analysis of observational studies in epidemiology: a proposal for reporting. Meta-analysis Of Observational Studies in Epidemiology (MOOSE) group. JAMA. 2000;283:2008-2012

12. Moher D, Liberati A, Tetzlaff J, Altman DG. Preferred reporting items for systematic reviews and meta-analyses: the PRISMA statement, 2007.

13. Higgins JP, Thompson SG, Deeks JJ. Altman DG. Measuring inconsistency in meta-analyses, 2008.

14. DerSimonian R, Laird N. Meta-analysis in clinical trials. Control Clin Trials. 1986;7(3):177-88.

15. Moustafa AH, Ali EM, Mohamed TM, Abdou HI. Oxidative stress and thyroid hormones in patients with liver diseases. Eur J Intern Med. 2009;20:7038.

16. Gokmen FY, Ahbab S, Ataoglu HE, Turker BC, Cetin F, Turker F, et al. FT3/FT4 ratio predicts nonalcoholic fatty liver disease independent of metabolic parameters in patients with euthyroidism and hypothyroidism. Clinics (Sao Paulo) 2016;71:221-5.

17. Bano A, Chaker L, Plompen EP, Hofman A, Dehghan A, Franco OH, et al. Thyroid function and the risk of nonalcoholic fatty liver disease: the Rotterdam Study. J Clin Endocrinol Metab. 2016;101(8):3204-11.

18. Ludwig U, Holzner D, Denzer C, Greinert A, Haenle MM, Oeztuerk S, et al. EMIL-Study: Subclinical and clinical hypothyroidism and nonalcoholic fatty liver disease: a cross-sectional study of a random population sample aged 18-65 years. BMC Endocr Disord. 2015;15:41.

19. Liu G, Zheng X, Guan L, Jiang Z, Lin H, Jiang Q, et al. Free triiodothyronine levels are positively associated with non-alcoholic fatty liver disease in euthyroid middle-aged subjects. Endocr Res. 2015;40:188-93.

20. Pagadala MR, Zein CO, Dasarathy S, Yerian LM, Lopez R, McCullough AJ. Prevalence of hypothyroidism in nonalcoholic fatty liver disease. Dig Dis Sci. 2012;57(2):528-34.

21. Ittermann $\mathrm{T}$, Haring $\mathrm{R}$, Wallaschofski $\mathrm{H}$, Baumeister SE, Nauck M, Dorr M, et al. Inverse association between serum free thyroxine levels and hepatic steatosis: results from the Study of Health in Pomerania. Thyroid. 2012;22:568-74. 
22. Xu C, Xu L, Yu C, Miao M, Li Y. Association between thyroid function and nonalcoholic fatty liver disease in euthyroid elderly Chinese. Clin Endocrinol. 2011;75:240-6.

23. Chung GE, Kim D, Kim W, Yim JY, Park MJ, Kim YJ, et al. Non-alcoholic fatty liver disease across the spectrum of hypothyroidism. J Hepatol. 2012;57:150-6.

24. Eshraghian A, Dabbaghmanesh MH, Eshraghian H, Fattahi MR, Omrani GR. Nonalcoholic fatty liver disease in a cluster of Iranian population: thyroid status and metabolic risk factors. Arch Iran Med. 2013;16:584-9.

25. Wang YF, Zhao JJ. The Relationship between the Broad Spectrum of Subclinical Hypothyroidism and NAFLD in Elderly Subjects (2014). Thesis for Master Degree, Shandong University, 2014.

26. Posadas-Romero C, Jorge-Galarza E, PosadasSanchez R, Acuna-Valerio J, Juarez-Rojas JG, Kimura-Hayama E, et al. Fatty liver largely explains associations of subclinical hypothyroidism with insulin resistance, metabolic syndrome, and subclinical coronary atherosclerosis. Eur J Endocrinol. 2014;171(3):319-25.

27. Parikh P, Phadke A, Sawant P. Prevalence of hypothyroidism in nonalcoholic fatty liver disease in patients attending a tertiary hospital in western India. Indian J Gastroenterol. 2015;34:169-73.

28. Gluvic Z, Zaric B, Resanovic I, Obradovic M, Mitrovic A, Radak D, et al. Link between metabolic syndrome and insulin resistance. Curr Vasc Pharmacol. 2017;15(1):30-9.

29. Polyzos SA, Aronis KN, Kountouras J, Raptis DD, Vasiloglou MF, Mantzoros CS: Circulating leptin in non-alcoholic fatty liver disease: a systematic review and meta-analysis. Diabetologia. 2016;59:30-43.

30. Demir Ş, Ünübol M, Aypak SÜ, İpek E, Aktaş S, Ekren GS, et al. Histopathologic Evaluation of Nonalcoholic Fatty Liver Disease in Hypothyroidism-Induced Rats. Int J Endocrinol. 2016;2016:5083746.

31. Zhang W, Tian LM, Han Y, Ma HY, Wang LC, Guo J, et al. Presence of thyrotropin receptor in hepatocytes: not a case of illegitimate transcription. J Cell Mol Med. 2009;13(11-12):4636-42.

Cite this article as: Alhussainy $\mathrm{F}$, Alharbi R, Alali A, Almutairi M, Aljawi M, Almodhaibri Y. Nonalcoholic fatty liver disease and thyroid function in adult patients. Int J Community Med Public Health 2018;5:2616-21. 